\title{
Flutuações de temperatura e umidade do solo em resposta à cobertura vegetal ${ }^{1}$
}

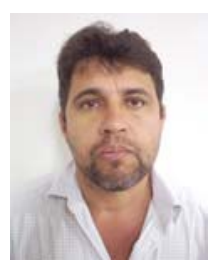

\author{
Milson L. de Oliveira ${ }^{2}$, Hugo A. Ruiz ${ }^{3}$, Liovando M. da Costa $^{3}$ \& Carlos E. G. R. Schaefer ${ }^{3}$ \\ ${ }^{1}$ Parte da Tese de Doutorado do primeiro autor, apresentada ao Programa de Pós-Graduação em Solos e Nutrição de \\ Plantas da Universidade Federal de Viçosa \\ ${ }^{2}$ Escola Agrotécnica Federal de Santa Teresa, Rod. ES 080, km 21. CEP 29660-000, Santa Teresa, ES. Fone: \\ (27) 3259-7878. E-mail: milsonlo@terra.com.br (Foto) \\ ${ }^{3}$ UFV, CEP 36570-000, Viçosa, MG. Fone: (31) 3899 2630. E-mail: hruiz@ufv.br; liovandomc@yahoo.br; \\ carlos.schaefer@ufv.br
}

Protocolo 43 - 28/2/2003 - Aprovado em 21/7/2005

\begin{abstract}
Resumo: Com o objetivo de verificar as flutuações de temperatura e umidade do solo em resposta à cobertura vegetal, realizou-se um experimento com sete diferentes situações de cobertura do solo, constituídas por solo sem cobertura, presença de vegetação espontânea, cultivo de mucuna e plantio de milho a 0, 30, 60 e $90^{\circ}$ em relação ao eixo leste-oeste. Dois meses após a semeadura, em janeiro de 1999, por igual período determinou-se o sombreamento nas entrelinhas do milho, às $8: 30,12: 30$ e 16:30 $\mathrm{h}$, como também, para todos os tratamentos, a temperatura e umidade do solo nas profundidades de 2,5, 5,0 e 7,5 cm; constatou-se diferença no sombreamento entre o cultivo de milho a $0^{\circ}$ e os outros ângulos testados nas determinações matutina e vespertina, mas tais diferenças não foram acompanhadas pela temperatura do solo que, neste caso, registrou valores intermediários entre o solo sem cobertura e os tratamentos com vegetação espontânea e mucuna. No tratamento sem cobertura verificou-se a maior amplitude de variação da temperatura ambiente acima da superfície do solo, registrando-se os menores valores de umidade e os maiores de temperatura do solo.
\end{abstract}

Palavras-chave: sombreamento, cobertura do solo, pedoclima, manejo de solo

\section{Soil temperature and moisture fluctuations in response to vegetation cover}

\begin{abstract}
An experimental study was carried out to evaluate the fluctuations of temperature and soil moisture in response to vegetation cover, using the following treatments: bare soil, natural weed cover, velvet bean, and maize at $0,30,60$ and $90^{\circ}$ in relation to a east-west axis. Two months after sowing in January 1999, for similar period the shadowed area between the lines at $8: 30,12: 30$ and $16: 30 \mathrm{~h}$, as well as for all treatments, the temperature and soil moisture at 2.5, 5.0 and $7.5 \mathrm{~cm}$ depths were measured. Differences in shadowing between maize cultivated at $\mathrm{O}^{\circ}$ and all other angles were observed in both morning and afternoon measurements. However, these differences were not accompanied by soil temperature, which showed intermediary values between the bare soil and the treatments with natural weed cover and velvet bean. In the bare soil treatment, the greatest temperature variation (amplitude) at the soil surface was observed, with lower soil moisture and higher temperature values.
\end{abstract}

Key words: shadowing, soil cover, pedoclimate, soil management

\section{INTRODUÇÃO}

O solo constitui-se em um dos principais fatores de produção, seja pela sua função como suporte para as plantas, ou pelo fornecimento de condições indispensáveis ao seu desenvolvimento, envolvendo água, nutrientes e calor; entretanto, a demanda por maiores produtividades tem levado, eventualmente, a uma considerável degradação deste recurso natural, em decorrência do manejo inadequado.

O desenvolvimento bem sucedido das culturas começa com condições favoráveis para a germinação e emergência das plântulas. Dentre os fatores que afetam a emergência está a presença de camadas superficiais adensadas. Essas camadas endurecidas, dependendo da coesão entre partículas podem, 
inclusive, ocasionar quedas na produtividade (Lemos \& Lutz, 1957).

Os estudos da morfologia do solo têm correlacionado o encrostamento a processos derivados da dissipação da energia cinética da chuva, por ocasião do contato com o solo, à deposição na superfície do solo de finas partículas em suspensão, ao final das chuvas e dos ciclos de umedecimento e secagem.

A formação de camadas superficiais adensadas pode ainda ser influenciada pela presença de cobertura vegetal ou de resíduos culturais sobre o terreno. Quando o solo está coberto pela vegetação ou por resíduos, uma grande proporção de gotas de chuvas é interceptada pela cobertura, que absorve parte da energia cinética antes desta alcançar a superfície do solo, reduzindo a formação de crostas; além de amortecer o impacto das gotas da chuva, vegetação ou resíduos reduzem o escoamento superficial e mantêm a umidade em níveis mais elevados (Duley, 1939).

A direção das fileiras das plantas cultivadas pode ser uma condicionante do endurecimento superficial do solo. Quando a fileira se encontra na direção predominante do vento e expõe mais o solo, ocorre maior evaporação da água do solo e, conseqüentemente, o endurecimento é mais pronunciado. Ressalta-se que a pulverização do solo, sua mineralogia e as condições climáticas variáveis, são importantes aspectos que devem ser considerados no processo de endurecimento de solos cultivados (Costa \& Jucksch, 1992).

Objetivou-se, com este trabalho, verificar a relação entre as flutuações de temperatura e umidade do solo e os níveis de insolação, utilizando-se sete diferentes situações de cobertura do solo, constituídas por solo sem cobertura, presença de vegetação espontânea, cultivo de mucuna e plantio de milho a $0,30,60$ e $90^{\circ}$ em relação ao eixo leste-oeste, sob condições de exposição à chuva natural, em um Argissolo intermediário para Cambissolo, do município de Viçosa, Minas Gerais.

\section{MATERIAL E MÉTODOS}

O ensaio de campo foi realizado em uma Estação Experimental da Universidade Federal de Viçosa, situada a $20^{\circ}$ $45^{\prime}$ de latitude Sul e $42^{\circ} 52^{\prime}$ de longitude Oeste, com altitude média de $650 \mathrm{~m}$. O solo é um Argissolo intermediário para Cambissolo, de textura muito argilosa, com predomínio de caulinita na fração argila e declividade máxima de 3\%.

O terreno utilizado na realização dos testes experimentais encontrava-se em pousio há mais de dois anos e sua maior parte havia sido cultivada, antes, com tomate (Lycopersicum esculentum L.). A área estava coberta por densa vegetação espontânea, constituída predominantemente por caruru-deporco (Amaranthus spinosus L.), colonião (Panicum maximum L.), capim-marmelada (Brachiaria plantaginea L.) e picão-preto (Bidens pilosa L.) (Lorenzi, 1994).

Antecedendo a realização dos testes de campo, determinouse a resistência do solo à penetração e se coletaram amostras nas profundidades de 0 a 10 e 10 a $20 \mathrm{~cm}$, para caracterização física, envolvendo análise textural, densidade do solo, densidade de partículas e curva característica de retenção de água do solo, realizando-se também a caracterização química dessas amostras.
Os sete tratamentos utilizados no ensaio foram dispostos em um delineamento em blocos casualizados, com quatro repetições. Quatro dos tratamentos corresponderam à cultura do milho (Zea mays L.), plantada em ângulos de 0, 30, 60 e $90^{\circ}$, tomando-se como referência o eixo leste-oeste; os outros três tratamentos se constituíram pelo cultivo de mucuna (Stizolobium spp.) que, depois de quarenta e cinco dias, cobriu quase que integralmente o solo; vegetação espontânea desenvolvida durante o ciclo da cultura, caracterizada como cobertura parcial, e tratamento totalmente sem vegetação, condição mantida pelo uso de herbicida (sem cobertura).

O experimento foi instalado em janeiro de 1999 e, nos últimos dois meses do ciclo da cultura fez-se, semanalmente, a medição da área sombreada, às 8:30, 12:30 e 16:30 h, com uma corda marcada (Olszevski et al., 1998). O sombreamento foi determinado utilizando-se corda de náilon branca, colocada a $20 \mathrm{~cm}$ do solo, no centro da unidade experimental, no sentido do comprimento do bloco, tendo esta já sido marcada com tinta vermelha, a cada $20 \mathrm{~cm}$. Em cada horário de leitura foram contados os pontos que se encontravam sombreados e calculada a sua proporção, em relação ao total de pontos da corda.

Nesses dois meses realizaram-se, ainda, duas vezes por semana, determinações da umidade e da temperatura do solo, nas profundidades de 2,$5 ; 5,0$ e $7,5 \mathrm{~cm}$, e da temperatura ambiente, a $10 \mathrm{~cm}$ da superfície. Realizaram-se as leituras às 8:30, 12:30 e 16:30 h, exceto para umidade do solo, cuja determinação ocorreu somente no horário das $8: 30 \mathrm{~h}$.

Na coleta das amostras de solo para determinação da umidade utilizou-se um cilindro metálico, com ponta afiada e abertura inferior com diâmetro menor que o corpo do coletor, a fim de diminuir o atrito durante a coleta e retirada do material. A amostra foi retirada do coletor pela extremidade oposta, com auxílio de um êmbolo e o solo recolhido foi disposto em uma calha, na qual a amostra foi fracionada com uma faca em subamostras de $2,5 \mathrm{~cm}$ de espessura e, depois de se eliminar $1,0 \mathrm{~cm}$ de cada extremidade, as subamostras de $0,5 \mathrm{~cm}$ foram colocadas em cápsulas devidamente identificadas, para determinação da umidade pelo método termogravimétrico (EMBRAPA, 1997).

A temperatura ambiente e a temperatura do solo foram determinadas utilizando-se um termômetro digital com haste constituída por um termopar de cobre-constantan, com sensibilidade de 0,1 grau.

Realizaram-se registros meteorológicos no decorrer do experimento, utilizando-se os dados fornecidos pela Estação Meteorológica da Universidade Federal de Viçosa, situada a $3 \mathrm{~km}$ da área experimental, (Tabela 1).

Ao término do experimento fez-se a remoção da cobertura vegetal para determinação da produção de matéria seca, ocasião em que também foram medidas as plantas de milho e feitas cinco medições ao acaso, nas unidades com mucuna e vegetação espontânea, para cálculo da altura média da vegetação, (Tabela 2).

Nas análises estatísticas utilizou-se o Sistema para Análises Estatísticas e Genéticas (SAEG) e, na análise de variância, a soma de quadrados para tratamentos foi desdobrada em contrastes ortogonais, para se verificar o efeito das coberturas vegetais e do ângulo de plantio para os tratamentos com milho. $\mathrm{Na}$ discussão dos resultados utilizou-se a denominação tendência para diferenças significativas a $20 \%$ pelo teste $\mathrm{F}$. 
Tabela 1. Características meteorológicas registradas no decorrer do experimento, relativas ao ano de 1999

\begin{tabular}{|c|c|c|c|c|}
\hline Característica & Janeiro $\mathrm{F}$ & Fevereiro & Março & Abril \\
\hline Precipitação total (mm) & 154,20 & 88,10 & 273,70 & 36,50 \\
\hline & 220,30 & 190,90 & 208,20 & 211,40 \\
\hline $\left.\mathrm{h} \mathrm{d}^{-1}\right)$ & & 6,82 & 6,72 & 7,05 \\
\hline & & 103,10 & & 74,40 \\
\hline Evapora & 3,38 & 3,68 & 2,55 & 2,48 \\
\hline Temp. $\mathrm{r}$ & 24,60 & 24,20 & 23,20 & 22,00 \\
\hline & & & 28,50 & 27,80 \\
\hline Temp. $\mathrm{r}$ & 18,90 & 18,40 & 17,90 & 16,10 \\
\hline Umidade relativa $\mathrm{n}$ & 78,25 & 78,08 & 84,26 & 82,26 \\
\hline & & 1,80 & 1,46 & 0,98 \\
\hline Pressão atmosférica média (mb) & 933,87 & 935,07 & 933,98 & 937,73 \\
\hline
\end{tabular}

Tabela 2. Características da vegetação ao término do ensaio

\begin{tabular}{|c|c|c|}
\hline Cobertura & Altura Média $(\mathrm{cm})$ & Matéria Seca $\left(\mathrm{kg} \mathrm{ha}^{-1}\right)$ \\
\hline Vegetação Espontânea & 126 & 6.072 \\
\hline Mucuna & 106 & 5.043 \\
\hline Milho & 192 & 14.113 \\
\hline $30^{\circ}$ & 204 & 14.658 \\
\hline $60^{\circ}$ & 203 & 11.437 \\
\hline $90^{\circ}$ & 187 & 13.116 \\
\hline
\end{tabular}

\section{RESULTADOS E DISCUSSÃO}

A medição do sombreamento produzido pelas plantas de milho iniciou-se quarenta e cinco dias após a implantação do ensaio, em três horários diferentes, considerando-se o ângulo de plantio. A fase inicial das determinações, quando as plantas ofereciam pouca proteção ao terreno, mostrou menor sombreamento a $0^{\circ}$, com as fileiras acompanhando a trajetória do sol, e maior a $90^{\circ}$, ou seja, perpendicular à trajetória do sol, nos horários das 8:30 e 16:30 h. Evidentemente, essa diferença no sombreamento ocorreu porque as fileiras dispostas a $0^{\circ}$ foram menos efetivas na interceptação dos raios solares.

No horário das 12:30 ho efeito do ângulo de plantio no sombreamento foi menos evidente e, com o crescimento das plantas, incrementou-se a cobertura do terreno, reduzindo as diferenças de sombreamento.

A Tabela 3 mostra os resultados médios do sombreamento e os respectivos contrastes ortogonais nos tratamentos com milho, determinados nos horários das 8:30, 12:30 e 16:30 h, no período de 18/2/99 a 15/4/99.

Seguindo-se a tendência das observações iniciais, verificaram-se diferenças significativas no sombreamento, quando contrastado o milho plantado no eixo leste-oeste com os outros ângulos de plantio, nos horários em que o sol incidiu com maior inclinação, e comportamento semelhante entre os quatro ângulos de plantio, na determinação das 12:30 h. Os valores observados de maior sombreamento do milho plantado a $90^{\circ}$ com respeito àquele plantado a $60^{\circ}$, foram reflexo da menor produção de massa obtida no plantio a $60^{\circ}$, (Tabela 2 ).

Verificou-se, ainda, que a disposição das folhas na planta alterou sua posição em função da direção da linha de plantio, com tendência a ficar perpendicular ao eixo do sol; este efeito
Tabela 3. Médias e contrastes ortogonais do sombreamento, considerando-se o ângulo de plantio do milho e o horário da determinação

\begin{tabular}{|c|c|c|c|}
\hline \multirow[b]{2}{*}{ Ângulo } & $8: 30$ & $12: 30$ & $16: 30$ \\
\hline & \multicolumn{2}{|c|}{ (h) } & \\
\hline 0 & 68 & 66 & 73 \\
\hline 30 & 80 & 72 & 83 \\
\hline 60 & 80 & 65 & 81 \\
\hline 90 & 83 & 72 & 87 \\
\hline \multicolumn{4}{|c|}{ Contrastes Ortogonais } \\
\hline $3(0)-30-60-90$ & $-39 *$ & -11 & $-33 *$ \\
\hline $2(30)-60-90$ & -3 & 7 & -3 \\
\hline $60-90$ & -3 & $-7^{\#}$ & $-5^{\#}$ \\
\hline
\end{tabular}

se mostrou mais evidente quando as plantas se encontravam mais próximas na linha de plantio e se constitui em recurso para melhorar as condições de captura da luz para realização da fotossíntese.

Os valores médios da temperatura ambiente, da temperatura e umidade do solo nas diferentes profundidades estudadas, são apresentados na Tabela 4.

Via de regra, a temperatura ambiente foi maior acima do solo sem cobertura e próxima entre os tratamentos com cobertura vegetal, comprovando que a temperatura próxima ao solo está diretamente relacionada com a sua cobertura, a qual tende a interceptar os raios solares que se dirigem à superfície, criando um microclima específico sob a mesma. Este comportamento corrobora com os resultados obtidos por Sandanielo (1983) o qual, ao comparar solo nu, cobertura morta e relva de gramínea, observou que a cobertura atuava como suavizadora das ondas térmicas, atenuando a temperatura.

$\mathrm{O}$ efeito da cobertura vegetal sobre a temperatura ambiente próxima à superfície do solo é melhor visualizado observandose a diferença nos valores médios de temperatura ao longo do dia. As maiores temperaturas foram registradas no horário das 12:30 h mas, independentemente do horário da determinação, acima do solo sem cobertura ocorreu a maior temperatura ambiente e na comparação entre a temperatura ambiente dos tratamentos com maiores coberturas oferecidas pela vegetação espontânea e mucuna e a cobertura obtida no plantio em linha, a temperatura registrada nas parcelas de milho foi superior, independentemente do ângulo de plantio.

No tratamento sem cobertura também se verificou a maior amplitude de variação da temperatura ambiente, registrandose menores valores médios às 8:30 h, mais altos às 12:30 h e intermediários às 16:30 h. A amplitude diária de variação da temperatura do solo depende do nível de cobertura, da capacidade calorífica do solo e da temperatura do ar (Salton \& Mielniczuck, 1995).

A temperatura do solo mostrou a mesma tendência da temperatura ambiente, porém com oscilações mais atenuadas em resposta aos tratamentos, e diminuiu com a profundidade; comportamento semelhante foi observado por Faria (1996). Em todos os horários estudados verificaram-se maiores valores no tratamento sem cobertura e menores para mucuna e vegetação espontânea, cujos resultados, segundo Amado et 
Tabela 4. Valores médios da temperatura ambiente acima do solo (TA), temperatura (T) e umidade (U) do solo a 2,5, 5,0 e $7,5 \mathrm{~cm}$ de profundidade, considerando-se a cobertura do solo e o horário da determinação

\begin{tabular}{|c|c|c|c|c|c|c|c|}
\hline \multirow{2}{*}{ Cobertura } & TA & Т 2,5 & T 5,0 & T 7,5 & $\mathrm{U} 2,5$ & $\mathrm{U} 5,0$ & $\mathrm{U} 7,5$ \\
\hline & \multicolumn{4}{|c|}{${ }^{\circ} \mathrm{C}$} & \multicolumn{3}{|c|}{$\mathrm{kg} \mathrm{kg}^{-1}$} \\
\hline \multicolumn{8}{|c|}{ Determinação às $8: 30 \mathrm{~h}$} \\
\hline Sem Cobertura & 24,7 & 25,5 & 24,6 & 24,1 & 0,300 & 0,329 & 0,332 \\
\hline Vegetação Espontânea & 23,5 & 22,4 & 22,1 & 22,1 & 0,352 & 0,358 & 0,379 \\
\hline Mucuna & 23,5 & 22,1 & 21,9 & 22,0 & 0,345 & 0,352 & 0,348 \\
\hline \multicolumn{8}{|l|}{ Milho } \\
\hline $0^{o(1)}$ & 24,0 & 23,2 & 22,8 & 22,6 & 0,334 & 0,349 & 0,355 \\
\hline $30^{\circ}$ & 23,9 & 22,8 & 22,4 & 22,4 & 0,354 & 0,355 & 0,360 \\
\hline $60^{\circ}$ & 24,1 & 22,9 & 22,6 & 22,5 & 0,340 & 0,345 & 0,357 \\
\hline $90^{\circ}$ & 24,1 & 22,8 & 22,7 & 22,5 & 0,337 & 0,367 & 0,380 \\
\hline \multicolumn{8}{|c|}{ Determinação às 12:30 h } \\
\hline Sem Cobertura & 30,3 & 33,6 & 32,0 & 30,0 & - & - & - \\
\hline Vegetação Espontânea & 28,8 & 25,7 & 24,8 & 24,1 & - & - & - \\
\hline Mucuna & 28,8 & 25,0 & 24,3 & 23,6 & - & - & - \\
\hline \multicolumn{8}{|l|}{ Milho } \\
\hline $0^{o(1)}$ & 29,4 & 27,5 & 26,6 & 25,7 & - & - & - \\
\hline $30^{\circ}$ & 29,3 & 27,2 & 26,2 & 25,2 & - & - & - \\
\hline $60^{\circ}$ & 29,5 & 28,3 & 27,0 & 25,7 & - & - & - \\
\hline $90^{\circ}$ & 29,4 & 27,8 & 26,7 & 25,6 & - & - & - \\
\hline \multicolumn{8}{|c|}{ Determinação às $16: 30 \mathrm{~h}$} \\
\hline Sem Cobertura & 28,1 & 31,1 & 31,6 & 31,0 & - & - & - \\
\hline Vegetação Espontânea & 27,0 & 26,0 & 25,8 & 25,4 & - & - & - \\
\hline Mucuna & 26,9 & 25,2 & 25,0 & 24,7 & - & - & - \\
\hline \multicolumn{8}{|l|}{ Milho } \\
\hline $0^{\mathrm{o}(1)}$ & 27,3 & 27,3 & 27,1 & 26,7 & - & - & - \\
\hline $30^{\circ}$ & 27,5 & 27,0 & 26,8 & 26,4 & - & - & - \\
\hline $60^{\circ}$ & 27,4 & 27,0 & 26,8 & 26,6 & - & - & - \\
\hline $90^{\circ}$ & 27,5 & 26,9 & 26,8 & 26,4 & - & - & - \\
\hline
\end{tabular}

al., (1990), mostram-se coerentes, considerando-se que os principais fatores ambientais que afetam a temperatura do solo são a radiação solar direta e difusa, a duração diária do brilho solar e a cobertura do solo, enquanto os fatores do solo são: o albedo, a condutância térmica, a atividade biótica, a estrutura e a umidade do solo, dentre outros

A temperatura do solo a $2,5 \mathrm{~cm}$ de profundidade, no tratamento sem cobertura, foi maior que a temperatura ambiente nos horários estudados, não se verificando o mesmo comportamento nos demais tratamentos; o tratamento sem cobertura também apresentou as maiores oscilações diárias de temperatura do solo, independentemente da profundidade, evidenciando-se a importância da cobertura vegetal na diminuição das flutuações térmicas ao longo do dia, enquanto as menores flutuações foram observadas nas unidades experimentais, com mucuna e vegetação espontânea, que apresentavam maior cobertura do solo.

$\mathrm{Na}$ comparação das temperaturas nas diferentes profundidades observam-se, sempre, valores mais elevados no solo sem cobertura. A vegetação espontânea e a mucuna, com cobertura semelhante do solo, praticamente não apresentaram diferença na temperatura.

Quando se considera o ângulo de plantio do milho observase maior temperatura do solo a $0^{\circ}$ na determinação das $8: 30 \mathrm{~h}$, quando começam a incidir os raios solares sobre o terreno e os outros ângulos de plantio apresentam maior sombreamento nas parcelas, (Tabela 3); esses resultados sofrem reversão às 12:30 h, acompanhando os resultados do sombreamento com menores valores no milho plantado a $60^{\circ}$. No final da tarde, a tendência é do solo mais coberto esfriar mais rapidamente, em razão do maior sombreamento notando-se, novamente, a maior temperatura no milho plantado a $0^{\circ}$.

Nas determinações da umidade do solo verificou-se o incremento com a profundidade de amostragem; na comparação entre tratamentos, o solo sem cobertura mostrou, nas três profundidades de amostragem estudadas, os menores valores de umidade. A perda de água foi facilitada pela maior exposição da superfície de evaporação e a maior temperatura registrada na ausência de vegetação; já na presença da cobertura vegetal, desconsiderados o tipo de vegetação e o ângulo de plantio do milho, os valores foram 
semelhantes, visto que a cobertura do solo o protege da insolação, amenizando a temperatura ambiente e do solo, além de interferir na ação do vento; basicamente, a cobertura dificulta o fluxo do vento e reduz sua capacidade de renovação da massa gasosa da superfície do solo, minimizando seu ressecamento.

\section{CONCLUSÕES}

1. Os resultados experimentais mostraram que a natureza da cobertura do solo e o nível de sombreamento influenciam diretamente nas flutuações de temperatura e umidade do solo.

2. Verificou-se oscilações mais expressivas quando o terreno se encontra sem cobertura e quando a direção de plantio da cultura facilita a exposição à insolação;

3. As variações na umidade e temperatura do solo tendem a diminuir com o aumento da profundidade de amostragem.

\section{LITERATURA CITADA}

Amado, T.J.C. Matos, A.T. Torres, L. Flutuação de temperatura e umidade do solo sob preparo convencional e em faixas na cultura da cebola. Pesquisa Agropecuária Brasileira, Brasília, v.24, p.625-631, 1990.

Costa, L.M.; Jucksch, I. Dia de campo sobre manejo e conservação de solos - Capinópolis. Viçosa: UFV, 1992. 28p. Boletim Técnico
Duley, F.L. Surface factors affecting the rate of intake of water by soil. Soil Science Society of America Proceedings, Madison, v.4, p.60-64, 1939.

EMBRAPA - Empresa Brasileira de Pesquisa Agropecuária. Centro Nacional de Pesquisa de Solos. Manual de métodos de análise de solo. 2.ed., Rio de Janeiro: EMBRAPA, 1997. $212 p$.

Faria, J.C. Dinâmica de água, comportamento térmico e selamento de um Podzólico Vermelho-Amarelo, em relação ao controle de plantas invasoras. Viçosa: UFV, 1996. 104p. Dissertação Mestrado

Lemos, P.; Lutz, J.F. Soil crusting and some factors affecting it. Soil Science Society of America Proceedings, Madison, v.21, p.485-491, 1957.

Lorenzi, H. Manual de identificação e controle de plantas daninhas. Nova Odessa: Plantarum, 1994. 299p.

Olszevski, N. Braga, A.P. Costa, L.M. Silva, H.R.F. Proposição de metodologia para avaliação da degradação de pastagens em propriedades rurais. In: Reunião Brasileira de Manejo e Conservação do Solo, 12, 1998, Fortaleza. Anais... Fortaleza: Sociedade Brasileira de Ciência do Solo, 1998. p.304-305.

Salton, J.C. Mielniczuck, J. Relações entre sistemas de preparo, temperatura e umidade de um Podzólico Vermelho-Escuro de Eldorado do Sul (RS). Revista Brasileira de Ciência do Solo, Campinas,v.19, p.313-319, 1995.

Sandanielo, A. Estudo do ciclo diário do regime térmico do solo de Viçosa MG, sob três condições de cobertura. Viçosa: UFV, 1983. 79p. Dissertação Mestrado 